\title{
The best time to invest in photovoltaic panels in Flanders
}

\author{
Jeroen Beliën \\ Liesje De Boeck \\ Jan Colpaert \\ Gert Cooman
}
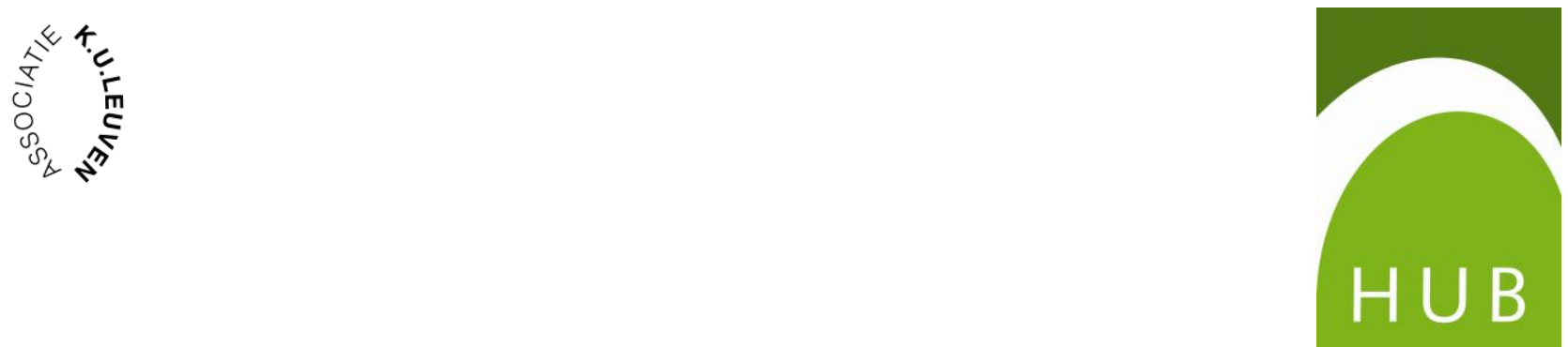


\title{
The best time to invest in photovoltaic panels in Flanders
}

\author{
Jeroen Beliën $^{1,2}$, Liesje De Boeck ${ }^{1,2, *}$, Jan Colpaert ${ }^{1,2}$, Gert Cooman \\ ${ }^{1}$ HUBrussel, Center for Informatics, Modeling and Simulation, Warmoesberg 26, 1000 Brussels, \\ Belgium \\ jeroen.belien@hubrussel.be \\ liesje.deboeck@hubrussel.be \\ ${ }^{2}$ Affiliated Researcher Katholieke Universiteit Leuven, Research Center for Operations Management, \\ Naamsestraat 69, 3000 Leuven, Belgium
}

\begin{abstract}
Up to now, there has been some controversy about green certificates (a form of subsidy) that are granted for the installation of photovoltaic (PV) panels in the Flemish residential sector. The Flemish government has already reduced the value of future green certificates, because they appeared to be excessively high. Currently, power providers have to pay for these certificates. Owners not having a PV installation suspect that they will be charged for those additional costs in the form of rising energy bills. As such, it seems that investing in PV panels would end up being the cheapest option for them in the long run. At the same time, we observe the following trends in analyzing costs and benefits in installing PV panels in the Flemish residential sector: the PV industry is booming causing PV panels to become cheaper; energy prices will continue to rise (with or without including the recovery of green certificates costs); tax revenues on the investment cost will be abolished; and the value of green certificates decreases when households postpone their investment in PV panels. It is therefore worth investigating when the investment in PV panels for the Flemish residential sector is optimal in terms of time. We compare the timing of different investments by analyzing their future value and return, embedded in a sensitivity analysis. By forecasting all relevant parameters, the analysis points out that the best period for investing in PV panels for the Flemish residential sector was between December 2010 or June 2011. After 2011, PV panels remain a responsible financial investment but with a decreasing rate of return. The results further indicate that investment in PV panels was and still remains over-subsidized. Therefore, the government should continue to decrease the subsidies in the near future. Apart from saving money, this would also stimulate the average Flemish household to invest in PV panels as soon as possible.
\end{abstract}

\section{Keywords:}

PV panels, investment timing, Flemish residential sector, economic analysis

\footnotetext{
* Corresponding author. Postal address: Center for Informatics, Modelling and Simulation, HUBrussel, Stormstraat 2, 1000 Brussels, Belgium. Tel.: +32 2609 8272; fax: +32 2217 6464. E-mail address: liesje.deboeck@hubrussel.be.
} 


\section{Introduction}

More than 40 years have passed since the first application of photovoltaic (PV) cells. An explosion of research and development in PV technology over recent decades has enabled PV systems to compete more closely with traditionally produced electricity. However, there still remains some distance to go. As PV technology has the potential to provide sustainable electricity, it has attracted a lot of attention from policy makers [1]. Up till now, governments worldwide have strongly supported renewable electricity generators by means of a direct subsidy or a feed-in tariff. This has allowed the PV industry to switch to mass production. By the end of 2009, the total yearly worldwide installed capacity reached 7200 megawatt (MW). By the end of 2010, this annual figure had doubled [2]. This large-scale production and further technological developments will assuredly tend to lower prices of PV panels even more.

The Flemish government provides support to the production of electricity from PV panels in the residential sector by different subsidies (e.g., green certificates). Note that the residential sector is generally known to be responsible for a large proportion of European energy consumption [3]. We refer to Section 2.2. for detailed information on these subsidies.

Recently, there has been some opposition to e.g., the payment for these green certificates, as the levels appear to be excessively high. Owners fear being saddled with making up for the cost of those payments through their rising energy bills. So it seems that investing in PV panels would end up being the cheapest option for them in the long run. The question then arises about the timing of this investment, since investment in a PV installation has a long life expectancy and one can only invest once.

This paper will investigate the most appropriate timing for investing in PV panels for the Flemish residential sector. Therefore, we will analyze costs and benefits according to different scenarios and use the results as input for calculating the future value and return of these investments.

The existing literature lacks studies on optimizing the timing of a PV investment in economic terms (i.e., by means of financial evaluation criteria) except for the paper by Ashuri et al. [4]. This paper uses real options theory in order to investigate the optimal timing for installing PV panels. They argue that the net present value (NPV) is not suitable for this analysis because of its deterministic nature. The future value (FV) we 
will use to perform the analysis has a lot in common with the NPV (see Section 3). But we try to overcome this limitation in two ways. Firstly, we take into account changes in the model parameters for future periods, and secondly we perform a sensitivity analysis for the most influential model parameters. Besides the technique that is used, the paper by Ashuri et al. [4] also differs from this work with respect to the focus on "Solar Ready Buildings". We do not include this aspect of the work of preparing dwellings for future PV installation.

Although the literature on optimizing the timing of a PV investment in economic terms is very scarce, a similar approach can be found in grid parity analyses. Grid parity analysis tries to determine the moment where PV electricity can compete with electricity prices from the traditional power grid. Bhandari and Stadler [5] applied this analysis to Germany and used the experience curve in order to estimate the future installation cost. This curve indicates how the future prices of a certain technology evolve. However, grid parity does not necessarily aim at economic optimization. As a consequence, it is beyond the scope of this paper to make a grid parity analysis for Flanders. We note that the experience curve applied to PV cells is not new. Several authors $[6,7,8]$ analyzed the use of this curve with respect to energy technologies in general and PV installations in particular. Also in a portfolio analysis, considering PV in future energy production, the experience curve is used for predicting cost reductions [9].

Apart from grid parity analysis, the scientific literature offers several other studies of residential PV installations worldwide from the perspective of profit maximizing. However, most investments are contemporary, and thus not comparable over time $[10,11,12,13]$. Note that location plays a major role in PV investment evaluation as productivity and subsidy legislation largely depend on the political and geographical location [11]. As a result, the manner of subsidizing may require a totally different approach in economic analysis.

We will proceed as follows. In Section 2, we present the formulae for calculating the costs and benefits related to investment in PV panels. We end this section by representing the build-up of the future value and return formulae. Section 3 answers the timing question by assigning generic values to the parameters of these formulae and by performing a sensitivity analysis for a number of parameters. The final section concludes with the major findings and points out possibilities for future research. 


\section{Model}

The model is designed using an Excel spreadsheet. The time is not a continuous variable in the design. The data were calculated and assessed for each month resulting in 12 outputs for each year.

Costs (investment cost and financing cost) and revenues (interest bonification, tax revenues, energy cost savings, green certificates and interest on uninvested capital) are the most important variables for a model to investigate the optimal timing of investment in PV panels. Insurance and maintenance costs are not significant and therefore are excluded from the analysis. The goal is to determine the optimal time for investments in PV panels between 2010 and 2018.

In Sections 2.1 and 2.2 we discuss the costs and revenues in detail and the formulae represent all costs and revenues discounted to the value at the time of investment. In order to be able to compare the possible investments, we calculate the future value of all investments at December $1^{\text {st }}, 2043$ and their return (see Section 2.3). This is the point in time equal to the end life of the panels corresponding to the latest possible investment (i.e., December $1^{\text {st }}, 2018$ ).

\subsection{Costs}

In what follows, we discuss how the investment cost of PV panels is obtained (Section 2.1.1) and which additional costs are generated if the investment requires borrowing money (Section 2.1.2).

\subsubsection{Investment cost in $P V$ panels}

In order to obtain the investment cost of a PV installation in the years to come, a forecast is necessary with respect to the future cost of a PV installation. Many factors impact the future cost. In general, a realistic estimation asks for a complex model with many variables. To keep the forecast comprehensible and straightforward, the theory underlying the experience curve will be applied. The experience curve is a tool that attempts to calculate the decrease in future prices of a certain technology using cumulative production forecasts. The numerous examples from literature (see Section 1) justify making use of the experience curve to predict the future prices of PV installations. The experience curve is defined using Eqs. (1), (2) and (3). $C_{i}$ represents the cost at time $i, C_{0}$ is the cost of the base year (which is at the beginning of 2010 in 
our model). $Q_{i}$ and $Q_{0}$ are the total installed capacity, further referred to as the cumulative production, at time $i$ and at the base year respectively, while $b$ is defined as the learning coefficient.

$C_{i}=C_{0}\left(\frac{Q_{i}}{Q_{0}}\right)^{b}$

$P R=(2)^{\mathrm{b}}$

$L R=1-P R$

Eq. (1) shows that the cost decreases by a fixed percentage for each doubling of cumulative production [14]. The parameter $b$ is used to calculate the progress ratio $(P R)$ and the learning rate $(L R) . L R$ is considered a cost or price reduction percentage upon each doubling of cumulative production [8].

Bhandari and Stadler [5] published an overview of investigated $P R$ values of PV installations. They show that the $P R$ is always close to $80 \%$ (corresponding with a $L R$ of 20\%). An important addition to the list is a recent publication of EPIA [15], reporting a $P R$ of $78 \%$ on a global scale. In what follows, we assume worldwide production in using the formulae for the learning curve. The goodness of fit (represented by $\mathrm{R}^{2}$ ) is always (for all studies) close to $95 \%$ [7]. This justifies the use of the experience curve.

Apart from the $P R$ value, we also need an estimation of $Q_{i}$, the cumulative production at time $i$. EPIA [2] has conducted a study in which the cumulative production (or capacity) is calculated on a global scale for the coming years. Two scenarios have been developed: the moderate scenario and the policy-driven scenario. These scenarios represent a pessimistic and an optimistic case respectively. Lloyd and Forest [16] extended these cases up to three additional scenarios based upon the evolution of the energy market (the peak oil fast-track scenario, the peak oil collapse scenario and the climate change scenario). All scenarios are represented in Fig. 1. It shows that the moderate scenario prognosis of EPIA [2] is more conservative as compared to the scenarios proposed by Lloyd and Forest [16]. Previous annual reports of EPIA have shown that their prognoses were always on the conservative side [17]. 


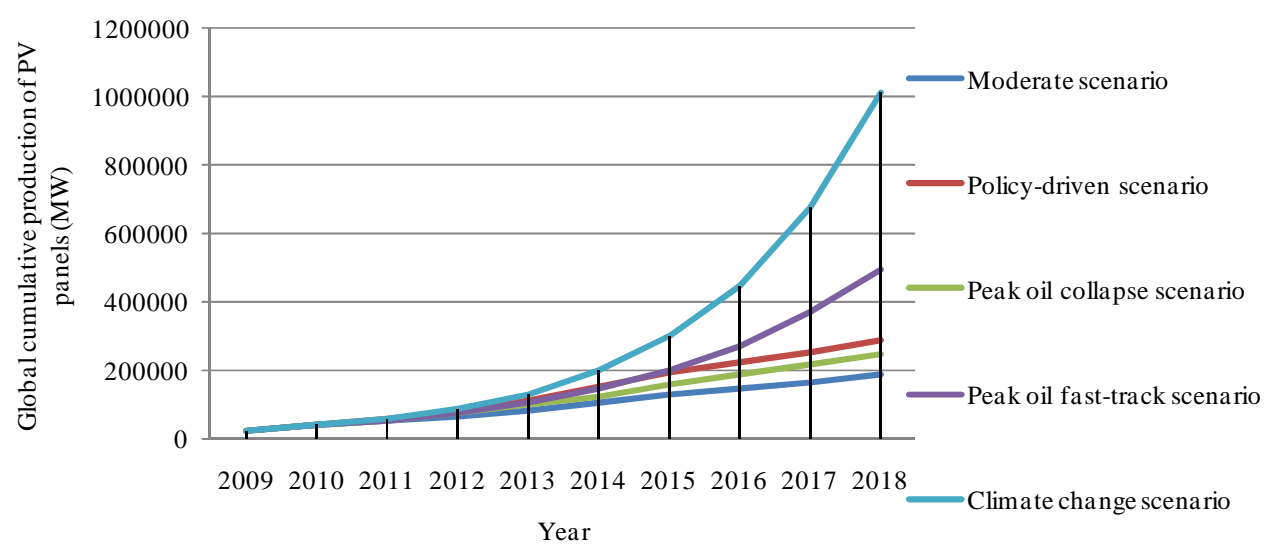

Figure 1: Evolution of the cumulative production of PV panels on a global scale for the different scenarios

Since we know all the necessary parameters, we can start by explaining the formula for calculating the investment cost in PV panels as represented in Eq. (4). $I C_{m t}$ represents the total investment cost at month $m$ of year $t$ for installing PV panels for an average household.

$I C_{m t}=P_{\text {peak }}\left(C_{0}(1+V A T)+\frac{C_{0}(1+V A T)}{10}\right)\left(\frac{Q_{m t}}{Q_{o}}\right)^{b}$

We assume $P R$ to be $79 \%$, which is the average value for $P R$ found in the overview of Bhandari and Stadler [5]. From $P R, b$ is deduced using Eq. (2). Consequently, the constant $b$ in Eq. (4) corresponds to a value of -0.34 . $P_{\text {peak }}$ represents the installed capacity, expressed in wattpeak (Wp). The model will use 5 kilowattpeak $(\mathrm{kWp})$ as a standard value, which represents the required capacity for an average household. $C_{0}$ is the cost of the installation of PV panels at the beginning of 2010. A reference value of $3.66 € / \mathrm{Wp}$ for $C_{0}$ is assumed. This value was obtained from the average of thirteen offers for an installation in January 2010. The value $3.66 € / \mathrm{Wp}$ is the price, excluding $6 \%$ value added tax (VAT). VAT of $6 \%$ relates to the cost when installing PV panels on a dwelling that is older than 5 years; VAT of $21 \%$ relates to the cost when installing PV panels on a dwelling that is not yet 5 years old. $C_{0}(1+V A T) / 10$ is the cost of the inverter after twelve years (i.e., the time of its replacement) as this cost amounts to ten percent of the original investment cost. $Q_{m t}$ is the total cumulative installed capacity worldwide in month $m$ of year $t$ as represented in Fig. 1 (note that capacity and 
production are used as synonyms and $Q_{m t}$ differs for each of the five scenarios). $Q_{0}$ is the total cumulative installed capacity worldwide at the start of 2010 and equals 22902 MW [2]. The results of Eq. (4) for all scenarios are represented in Fig. 2.

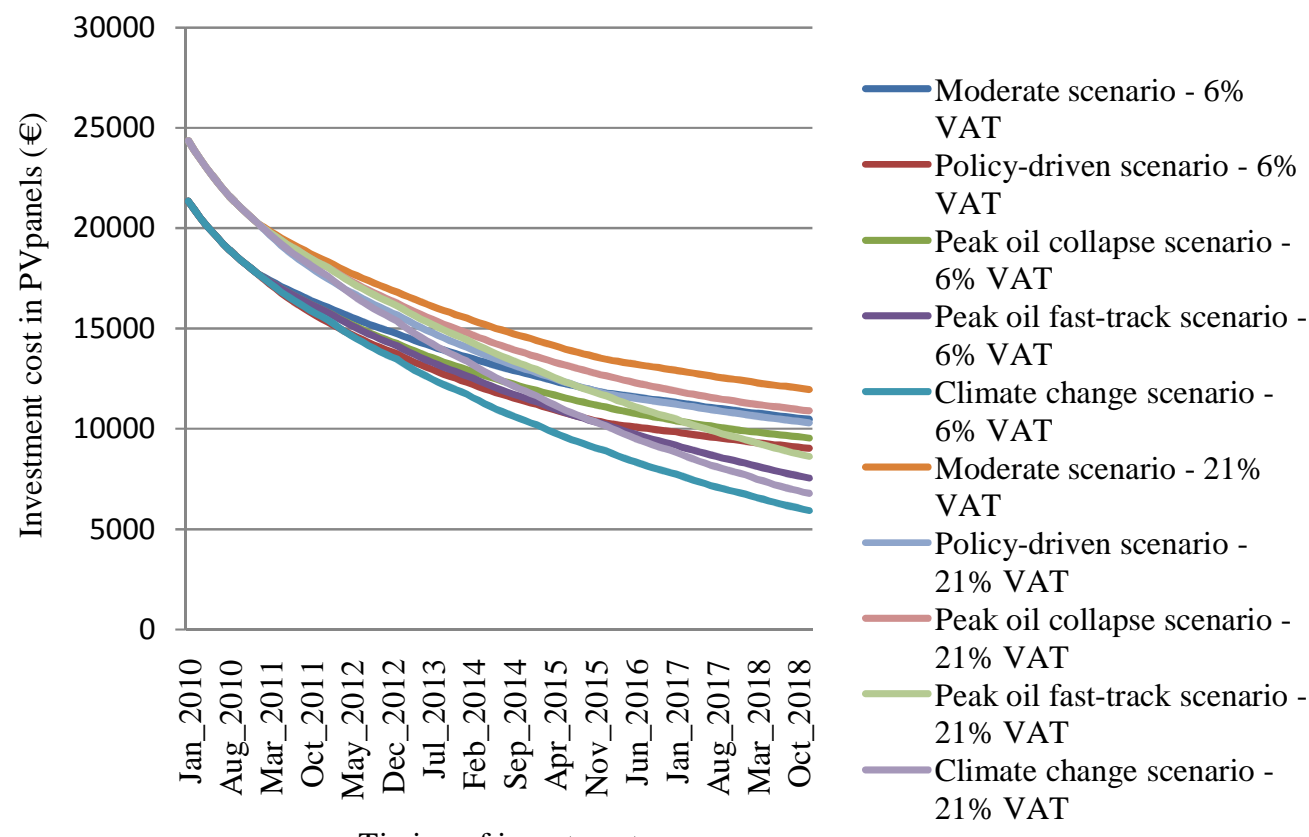

Figure 2: Investment costs for an average household in the event of $6 \%$ and $21 \%$ VAT and for different scenarios for the cumulative production of PV panels worldwide

\subsubsection{Financing costs for investing in PV panels}

Investment in PV panels may require borrowing money. In what follows, we will assume that the loan covers the total amount of the initial investment cost as calculated in the previous section. For investment in PV panels, a "green loan" can be obtained from the bank (limited to $15000 €$ ). To finance this type of investment, the bank charges an annual interest rate $(p)$. We assume $p$ to be $3.68 \%$ for a loan duration (n) equal to 5 years. This percentage includes interest bonification. The latter is an additional support measure from the Flemish government. It boils down to a subsidy which is equivalent to $1.5 \%$ of the loan cost (see Section 2.2.1). Besides this bonification, a tax revenue on $40 \%$ of the remaining interest of the loan can be obtained (see Section 2.2.2). We assume that the investor opts for fixed annuities represented by $A_{Q_{-} p}$ in the event of an annual interest rate equal to $p$ when investing $\mathrm{Q}$ $€$. The total interest payments occur at the beginning of each term and are represented 
on the right-hand side of Eq. (5). $F C_{m t}$ represents the additional financing costs (on top of the investment cost) when investing in month $m$ of year $t$.

$F C_{m t}=\left(\sum_{i=0}^{n-1} \frac{A_{I C_{m} t-p}}{(1+p)^{i}}\right)-I C_{m t}$

\subsection{Revenues}

In what follows, we represent the standard types of revenues that are obtained in investing in PV panels. Besides the subsidies, i.e., interest bonification (Section 2.2.1), tax revenues (Section 2.2.2), green certificates (Section 2.2.4), we also have to take into account energy cost savings (section 2.2.3) and capital interest revenues gained by investing later than at the start of 2010 (Section 2.3).

\subsubsection{Interest bonification}

The annual interest rate ( $p$ ) of the green loan (see Section 2.1.2) includes interest bonification. This boils down to a subsidy from the government which is equivalent to $1.5 \%$ of the loan cost in the year of investment. However, from January $1^{\text {st }}, 2012$ on, the green loans for investing in PV panels will be omitted.

The value of this interest bonification $\left(I B_{m t}\right)$ is represented in Eq. (6).

$$
\begin{aligned}
& I B_{m t}=f(x)= \\
& \left\{\begin{array}{c}
F C_{m t}-\left[\left(\sum_{i=0}^{n-1} \frac{A_{15000 \_(p-0.015)}}{(1+(p-0.015))^{i}}\right)-15000\right], I C_{m t}>15000 \text { and } t \leq 2011 \\
F C_{m t}-\left[\left(\sum_{i=0}^{n-1} \frac{A_{I C_{m t}(p-0.015)}}{(1+(p-0.015))^{i}}\right)-I C_{m t}\right], I C_{m t} \leq 15000 \text { and } t \leq 2011 \\
0, t>2011
\end{array}\right.
\end{aligned}
$$

$A_{Q_{-}(p-0.015)}$ represents the fixed annuities in the event of an interest rate equal to the interest rate $(p)$ minus the interest bonification (1.5\%) when lending $Q €$.

\subsubsection{Tax revenues}

The federal government grants a tax reduction of $40 \%(r)$ on the investment cost. However, the maximum tax reduction $\left(M_{t}\right)$ per year is set at $3600 €$ for $t$ equal to 2010 and 3680 for $t$ equal to 2011. The tax reduction will disappear for investments in 2012 or later. If the dwelling is older than 5 years, the tax reduction can be spread over 4 
years; if the dwelling is less than 5 years old, the tax reduction is only valid for one year. However, in total (i.e., spread over 4 years or 1 year), the tax reduction may not exceed $40 \%$ ( $r$ ) of the investment cost. $T R_{m t}$, which can be found in Eq. (7), represents the total fiscal reduction on the investment cost when investing in month $m$ of year $t$. $T_{i}$ (with $i=t+1, \ldots, t+4$ ) indicates the amount of tax reduction in the years $i$ following the year of investment (year $t$ ). On top of this yearly tax reduction, the local tax rate $q$ generates additional tax revenues. This local tax rate is represented by $q$ and is set at $7.5 \%$. The parameter $d$ (equal to $3 \%$ ) is assumed to be the discount rate (or cost of capital) in what follows.

$T R_{m t}=\left\{\begin{array}{c}\sum_{i=1}^{4}(1+q) \frac{T_{i}}{(1+d)^{i}}, V A T=6 \% \text { and } t=2010 \text { or } 2011 \\ \frac{(1+q) \min \left\{r\left(I C_{m t}\right), M_{t}\right\}}{(1+d)}, V A T=21 \% \text { and } \mathrm{t}=2010 \text { or } 2011 \\ 0, \mathrm{t} \geq 2012\end{array}\right.$

with $T_{i}=\left\{\begin{array}{r}0, r\left(I C_{m t}\right)-(i-1) M_{t} \leq 0 \\ \min \left\{\left(r\left(I C_{m t}\right)-(i-1) M_{t}\right), M_{t}\right\}, r\left(I C_{m t}\right)-(i-1) M_{t}>0\end{array}\right.$

Next to the interest bonification of the green loan, a tax rebate of $40 \%$ of the remaining interest of this green loan can be obtained. This is represented by $T R_{m t, g l}$ in Eq. (8) (the subscript $g l$ stands for "green loan"). The interest amount paid in the $i^{\text {th }}$ year for a green loan of $Q €$ to finance a PV installation is indicated by the symbol $I_{Q_{i} i} \cdot$

$T R_{m t, g l}=\left\{\begin{array}{c}\sum_{i=0}^{n-1} \frac{r\left(I_{15000 \_}\right)}{(1+(p-0.015))^{i}}, I C_{m t}>15000 \text { and } t \leq 2011 \\ \sum_{i=0}^{n-1} \frac{r\left(I_{I C_{m t} \_}\right)}{(1+(p-0.015))^{i}}, I C_{m t} \leq 15000 \text { and } t \leq 2011 \\ 0, t>2011\end{array}\right.$

\subsubsection{Energy cost savings $\left(E C S_{m t}\right)$}

To estimate the future energy cost savings of an investment in PV panels, a correct calculation of the electricity prices during the life expectancy of the panels is required. A further increase in electricity prices is obviously beneficial to the owner of a PV installation.

Nowadays, solar panels have a life expectancy varying between 20 and 30 years. Hence for this model, a life expectancy of 25 years is chosen. This means that if 
someone is about to invest until 2018 (the final year in which renewable electricity certificates will be granted), he should have an idea of the electricity prices until 2043 to calculate his returns. This requires a forecast over a very long term. There are studies aiming for long-term forecasts of electricity prices by means of complex modeling including all relevant factors (see, e.g., the EMELIE-model [18] and the dynLEM-model [19]). Indeed, projecting the past onto the present does not appear to be that simple [20]. The results of the dynLEM-model show an average annual price increase ranging from $1 \%$ to $3 \%$ [19]. Bhandari and Stadler [5] forecast an annual increase in electricity prices between $2 \%$ and $4 \%$. Because the Belgian market of electricity production can be considered as being monopolized the figure will be closer to $4 \%$.

The total yield (in terms of $\mathrm{kWh}$ ) of the PV investment depends on the installed capacity. Wattpeak (Wp) is the unit of capacity of a PV panel under standard testing conditions. An installation with a capacity of $1 \mathrm{kWp}$ oriented to the south and with a $30^{\circ}$ inclination angle, will produce an optimal $850 \mathrm{kWh}$ on a yearly base. An alternative orientation or inclination leads to a reduced electricity yield (Table 1).

Table 1: Output in terms of inclination and orientation

\begin{tabular}{lll}
\hline Orientation & Slope $30^{\circ}$ & Slope $45^{\circ}$ \\
\hline South & $100 \%$ & $98 \%$ \\
South-East or South-West & $96 \%$ & $93 \%$ \\
East or West & $85 \%$ & $79 \%$ \\
\hline
\end{tabular}

The energy cost savings $\left(E C S_{m t}\right)$ in Eq. (9) are calculated by multiplying the electricity prices (in $€ / \mathrm{kWh}$ ) and the total yield (in $\mathrm{kWh}$ ) over the whole time span of 25 years.

$$
\begin{aligned}
& E C S_{m t}= \\
& \sum_{i=1}^{25} \frac{E_{0}(1+g)^{i-1} 850 P_{\text {peak }} l(1-(i-1) z)}{(1+d)^{i}}-E_{0} 850 P_{\text {peak }} l\left(1-s_{m}\right)+ \\
& \frac{E_{0}(1+g)^{25} 850 P_{\text {peak }} l(1-25 z)\left(1-s_{m}\right)}{(1+d)^{26}}
\end{aligned}
$$

$E_{0}$ represents the electricity price in the starting year (2010) and is set at 0.1959 $€ / \mathrm{kWh}$. The price in the years that follow are calculated by taking into account the 
electricity price growth rate $(g)$, set at $4 \%$. The first term in Eq. (9) represents the discounted energy cost savings from the first until the $25^{\text {th }}$ year of installation. The value $l$ is the output as represented in Table 1 (i.e., $l$ equals $100 \%$ for a south orientation and inclination slope of $30^{\circ}$ ). The value $z$ is a parameter incorporating degradation of the PV system. This degradation is considered to be linear and a standard value of $0.44 \%$ (which corresponds to a linear degradation of $11 \%$ [22] over a time period of 25 years) is set for $z$. The second term accounts for the yield "loss" in the first year. This loss corresponds to the months in the first year in which the installation has not yet been installed. The third term includes the remaining period during the last year of production. The index $m$ corresponds to the month in which the installation has started to work. $s_{m}$ is the percentage of yield that can be expected on average for the remainder of the year (starting in month $m$ ). The values for $s_{m}$ (applicable for Belgium) are represented in Table 2. Table 2 is based on the share of monthly sunshine in a year. This share is relatively low for the first and last months of the year (for example, three percent for January, two percent for December).

Table 2: Yield for the remaining period when installing PV panels in a specific month corresponding to the share of sunshine per month. Source: KMI [22]

\begin{tabular}{llllllllllll}
\hline Jan & Feb & Mar & Apr & May & Jun & Jul & Aug & Sep & Oct & Nov & Dec \\
\hline$s_{1}$ & $s_{2}$ & $s_{3}$ & $s_{4}$ & $s_{5}$ & $s_{6}$ & $s_{7}$ & $s_{8}$ & $s_{9}$ & $s_{10}$ & $s_{11}$ & $s_{12}$ \\
$100 \%$ & $97 \%$ & $92 \%$ & $84 \%$ & $72 \%$ & $59 \%$ & $46 \%$ & $32 \%$ & $20 \%$ & $11 \%$ & $6 \%$ & $2 \%$ \\
\hline
\end{tabular}

\subsubsection{Green certificates}

The Flemish government provides support for the production of electricity from PV panels by means of green certificates (subject to some conditions such as, e.g., a sufficiently insulated roof,...). For each $1000 \mathrm{kWh}$ electricity generated by PV panels, the owner receives a green certificate. The concrete value of these certificates and the time period depend on the timing of the investment in PV panels and is represented in Table 3. The symbol $F_{m t}$ represents the value of a green certificate when having invested in month $m$ of year $t(t=2010, \ldots, 2018)$.

Table 3: Scheme of green certificates (in $€$ ) granted by the Flemish government

\begin{tabular}{llllllllll}
\hline$F_{m t}$ & 2010 & 2011 & 2012 & 2013 & 2014 & 2015 & 2016 & 2017 & 2018 \\
\hline Jan & 350 & 330 & 250 & 190 & 150 & 110 & 90 & 90 & 90 \\
Feb & 350 & 330 & 250 & 190 & 150 & 110 & 90 & 90 & 90
\end{tabular}




\begin{tabular}{llllllllll} 
Mar & 350 & 330 & 250 & 190 & 150 & 110 & 90 & 90 & 90 \\
Apr & 350 & 330 & 230 & 190 & 150 & 110 & 90 & 90 & 90 \\
May & 350 & 330 & 230 & 190 & 150 & 110 & 90 & 90 & 90 \\
Jun & 350 & 330 & 230 & 190 & 150 & 110 & 90 & 90 & 90 \\
Jul & 350 & 300 & 210 & 190 & 150 & 110 & 90 & 90 & 90 \\
Aug & 350 & 300 & 210 & 190 & 150 & 110 & 90 & 90 & 90 \\
Sep & 350 & 300 & 210 & 190 & 150 & 110 & 90 & 90 & 90 \\
Oct & 350 & 270 & 210 & 190 & 150 & 110 & 90 & 90 & 90 \\
Nov & 350 & 270 & 210 & 190 & 150 & 110 & 90 & 90 & 90 \\
Dec & 350 & 270 & 210 & 190 & 150 & 110 & 90 & 90 & 90 \\
\hline Years & 20 & 20 & 20 & 15 & 15 & 15 & 15 & 15 & 15 \\
granted & & & & & & & & & \\
\hline
\end{tabular}

Note that the time period in which these green certificates are granted is 20 years when investing in PV panels before 2013. As of 2013, the time period is reduced to fifteen years. $F_{m t}$ is determined by the Flemish government. The discounted value of these green certificates $\left(G C_{m t}\right)$ is represented in Eq. (10).

$$
\begin{aligned}
& G C_{m t}= \\
& \left\{\begin{array}{l}
\sum_{i=1}^{20} \frac{F_{m t} \frac{850 P_{\text {peak }} l(1-(i-1) z)}{1000}}{(1+d)^{i}}-F_{m t} \frac{850 P_{\text {peak }} l\left(1-s_{m}\right)}{1000}+\frac{F_{m t} \frac{850 P_{\text {peak }} l(1-20 z)\left(1-s_{m}\right)}{1000}}{(1+d)^{21}}, t<2013 \\
\sum_{i=1}^{15} \frac{F_{m} \frac{850 P_{\text {peak }} l(1-(i-1) z)}{1000}}{(1+d)^{i}}-F_{m t} \frac{850 P_{\text {peak }} l\left(1-s_{m}\right)}{1000}+\frac{F_{m t} \frac{850 P_{\text {peak }} l(1-15 z)\left(1-s_{m}\right)}{1000}}{(1+d)^{16}}, t \geq 2013
\end{array}\right.
\end{aligned}
$$

Eq. (10) is equivalent to Eq. (9) with the adjustment that the green certificates can only be obtained for each $1000 \mathrm{kWh}$ produced.

\subsection{Evaluation criteria}

Our objective is to determine the optimal timing of investing in PV panels by comparing the costs and revenues over time. Thus, the time and the time value of money play an important role. The classical evaluation criteria for this type of investments are the net present value (NPV), the internal rate of return (IRR), and the payback period (PBP). However, these criteria have the following disadvantages. Comparing the NPV of different investments makes sense only if the investments take place at the same time and have the same investment value. The IRR assumes the cash 
inflows are reinvested with the same return as the investment. In reality, the households will never be able to reinvest the profit of their PV panels back into these panels. The PBP does not take the time value of money into account and does not say anything about the investment beyond the time when it is recouped completely. That is why we will use none of those measures, but will rely on the future value of all investments. More specifically, we calculate the (future) value of all possible investment timings at December $2043\left(F V_{m t}\right)$. That is because this is the point in time equal to the end life of the panels corresponding to the latest possible investment (i.e., December $1^{\text {st }}$, in 2018).

In order to have a fair comparison, we will start from the amount that can be invested in January 2010. This amount is equal to $I C_{m t}$ with $m=1, t=2010$ and $V A T=21 \%$ (= $24359.81 €=S$ ) since this is the highest of all investment costs. Investing later than January 2010, causes the investment to yield interest till the time of investment. On top of that, the difference between $S$ and the investment cost when investing after January 2010 also yields interest after the investment time. This yield $\left(Y_{m t}\right)$ is represented in Eq. (11).

$Y_{m t}=\left[S(1+d)^{\left(\frac{m-1}{12}+(t-2010)\right)}\right]-I C_{m t}$

Apart from the future value of all investments, we can also calculate the return on each investment $\left(R_{m t}\right)$. Both the formulae for the future value and the return are represented in Eqs. (12) and (13).

$$
\begin{aligned}
& F V_{m t}=\left[-F C_{m t}+I B_{m t}+T R_{m t}+T R_{m t, g l}+E C S_{m t}+G C_{m t}+Y_{m t}\right](1+ \\
& \text { d) }{ }^{\left[33-\frac{1}{12}-\left(\frac{m-1}{12}+(t-2010)\right)\right]} \\
& R_{m t}=\left[\left(\frac{F V_{m t}}{S}\right)^{\left(\frac{1}{33-\frac{1}{12}}\right)}\right]-1 .
\end{aligned}
$$

Note that in Eq. (12), the factor projecting the costs and revenues at the time of investment in PV panels has an exponent of $33-\frac{1}{12}-\left(\frac{m-1}{12}+(t-2010)\right)$. This 
exponent represents the number of years between the time of investment and December $1^{\text {st }}, 2043$.

\section{Results}

The models for $F V_{m t}$ and $R_{m t}$ with standard values for all parameters are discussed in Section 3.1. Some sensitivity analysis is performed in Section 3.2.

\subsection{The generic model}

In the generic model (base scenario), we use standard values for all parameters. These values are represented in Table 4.

Table 4: The parameters of the generic model

\begin{tabular}{|c|c|c|c|}
\hline Description & Symbol & Unit & Value \\
\hline Cost of PV panels at Jan $1^{\text {st }}, 2010$ when VAT $=6 \%$ & $C_{0}$ & $€ / \mathrm{kWh}$ & 3.88 \\
\hline Cost of PV panels at Jan $1^{\text {st }}, 2010$ when VAT $=21 \%$ & $C_{0}$ & $€ / W \mathrm{p}$ & 4.43 \\
\hline Installed capacity worldwide at Jan $1^{\text {st }}, 2010$ & $Q_{0}$ & MW & 22902 \\
\hline Progress ratio & $P R$ & $\%$ & 79 \\
\hline Learning coefficient & $b$ & & -0.34 \\
\hline Learning rate & $L R$ & $\%$ & 21 \\
\hline Installed capacity for an average household & $P_{\text {peak }}$ & $\mathrm{kWp}$ & 5 \\
\hline Duration loan & $n$ & years & 5 \\
\hline Interest rate loan & $p$ & $\%$ & 3.68 \\
\hline Local tax rate & $q$ & $\%$ & 7.5 \\
\hline Maximum tax revenue (for $t=2010$ ) & $M_{t}$ & $€$ & 3000.00 \\
\hline Maximum tax revenue (for $t=2011$ ) & $M_{t}$ & $€$ & 3680.00 \\
\hline Maximum tax reduction percentage & $r$ & $\%$ & 40 \\
\hline Electricity price 2010 & $E_{0}$ & $€ / \mathrm{kWh}$ & 0.1959 \\
\hline Electricity price growth rate & $g$ & $\%$ & 4 \\
\hline Yearly degradation rate of the yield of PV panels & $z$ & $\%$ & 0.44 \\
\hline $\begin{array}{l}\text { Factor that accounts for reduced yield, based on } \\
\text { orientation and inclination of PV panels }\end{array}$ & $l$ & $\%$ & 100 \\
\hline $\begin{array}{l}\text { Percentage of yield that can be expected on average for } \\
\text { the remainder of the year }\end{array}$ & $s_{m}$ & $\%$ & Table 2 \\
\hline $\begin{array}{l}\text { Value of a green certificate when having invested in } \\
\text { month } m \text { of year } t\end{array}$ & $F_{m t}$ & $€$ & Table 3 \\
\hline Discount rate & $d$ & $\%$ & 3 \\
\hline $\begin{array}{l}\text { Initial investment value (at Jan } 1^{\text {st }}, 2010 \text { when VAT = } \\
21 \% \text { ) }\end{array}$ & $S$ & $€$ & 24359.81 \\
\hline
\end{tabular}


We will use all parameters of Table 4 in Eqs. (12) and (13) and combine it with the different cumulative production of PV panels-scenarios described in Section 2.1. The results are represented in Figs. 3, 4, 5 and 6.

Figs. 3, 4, 5 and 6 clearly show that the optimal investment timing for the base scenario is December 2010 for all cases with VAT equal to 6\% and June 2011 for all cases with VAT equal to $21 \%$. When investing after 2011, the optimal timing for the base scenario is March 2012, except for the climate change scenario for both VAT tariffs and the peak-oil fast track scenario for VAT equal to 6\% where it is December 2018). If $S$ is not invested at all, the future revenue value (excluding $S$ ) equals $40091.62 €\left(=S(1+d)^{33-1 / 12}-S\right)$ and the return equals the discount rate $(d=3 \%)$. Figs. 3 , 4, 5 and 6 illustrate that investing in PV panels always renders a future value/return that is at least 2.55/1.49 times higher than not investing. It also worth noticing that the investment has a larger return when lending money than when not lending money for the investment in PV panels in the event that the green loan exists (before 2012). More specifically, the green loan is beneficial if " $p-0.015-r(p-0.015)<d$ ”. Comparing Figs. 3 and 4 reveals that VAT has a major impact in the short term. The future value of investments with VAT equal to $21 \%$ is significantly lower than for VAT equal to $6 \%$. As such, it might be advisable to delay the investment till the dwelling is 5 years old. Given the age of a dwelling that is not yet 5 years old, Figs. 3 and 4 include all information to answer the question of whether to delay the investment or not. Looking at Figs. 3, 4, 5 and 6, it is advisable to invest in PV panels as soon as possible (knowing that green certificates will probably be cut back more than represented in Table 3). After 2011, the future value decreases rather firmly. In 2013, the future value stabilizes somewhat till the end of 2016 and then increases once more in the years that follow. The explanation for this lies in the fact that in the last three years (2016, 2017 and 2018), the green certificates remain constant while the PV panels continue to get cheaper.

Note that the drops in Figs. 3, 4, 5 and 6 over certain time periods always correspond to a lowering in the value of green certificates. 


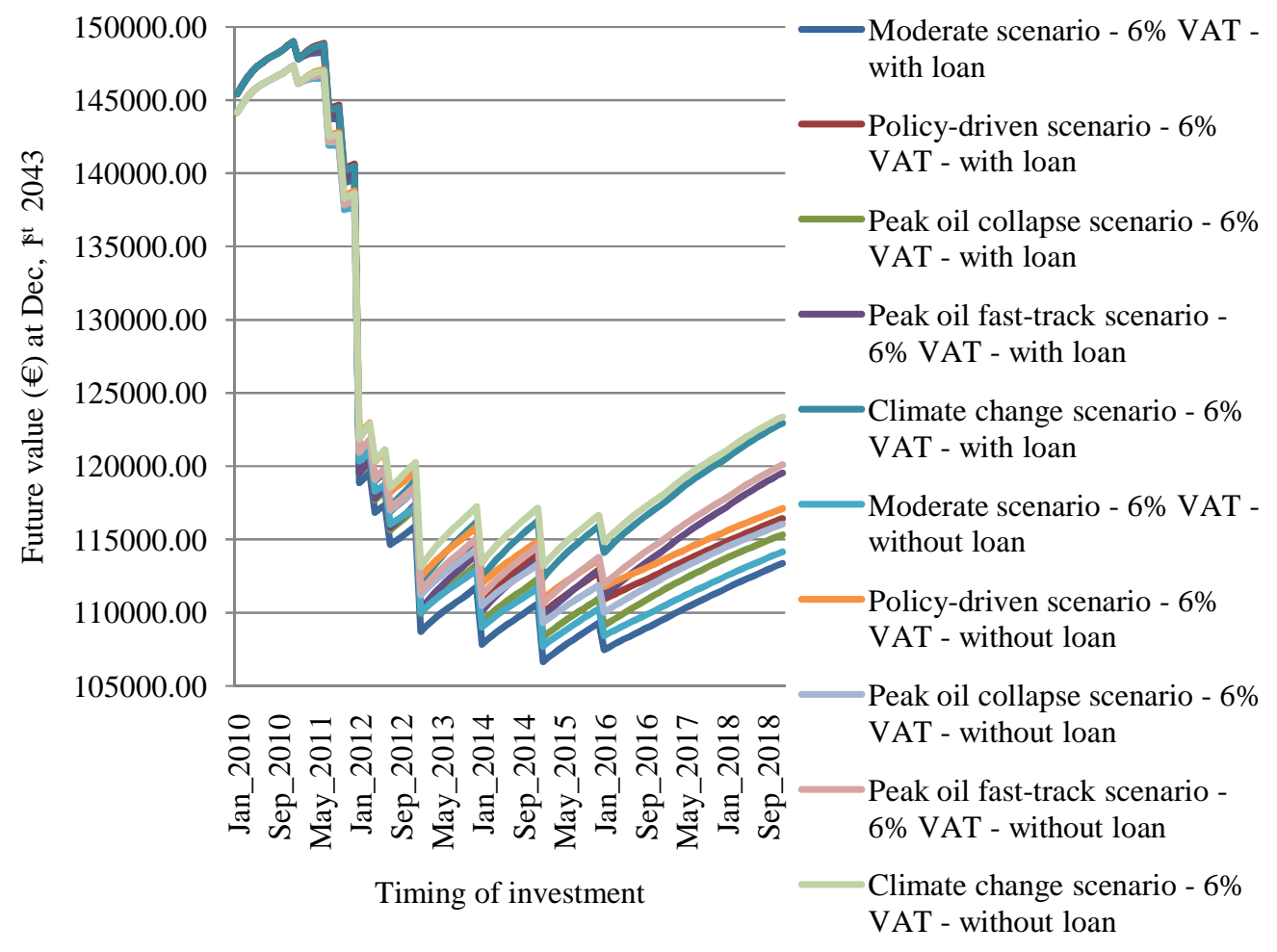

Figure 3: The future value of the investment for the base scenario and VAT equal to $6 \%$

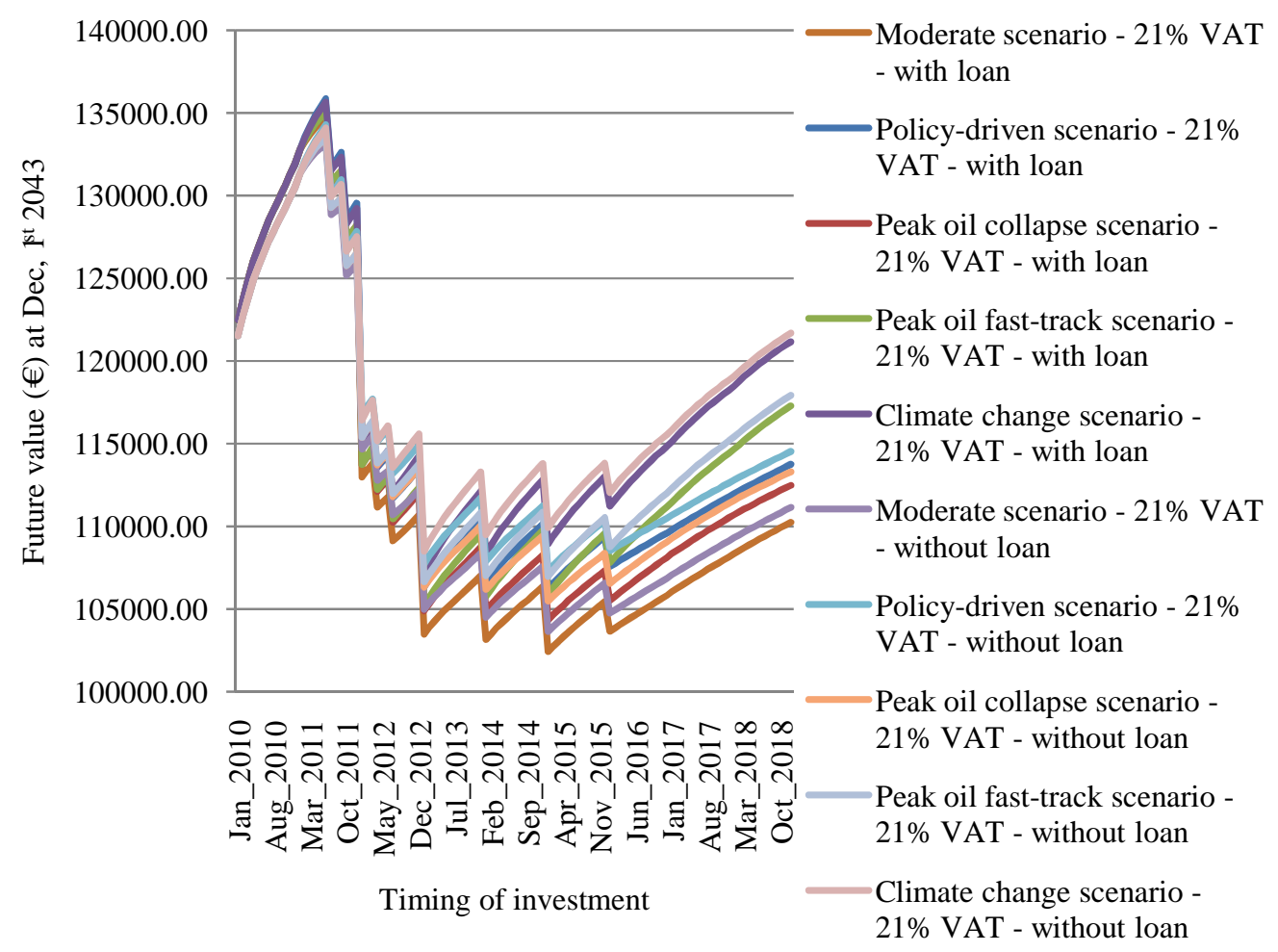

Figure 4: The future value of the investment for the base scenario and VAT equal to $21 \%$ 


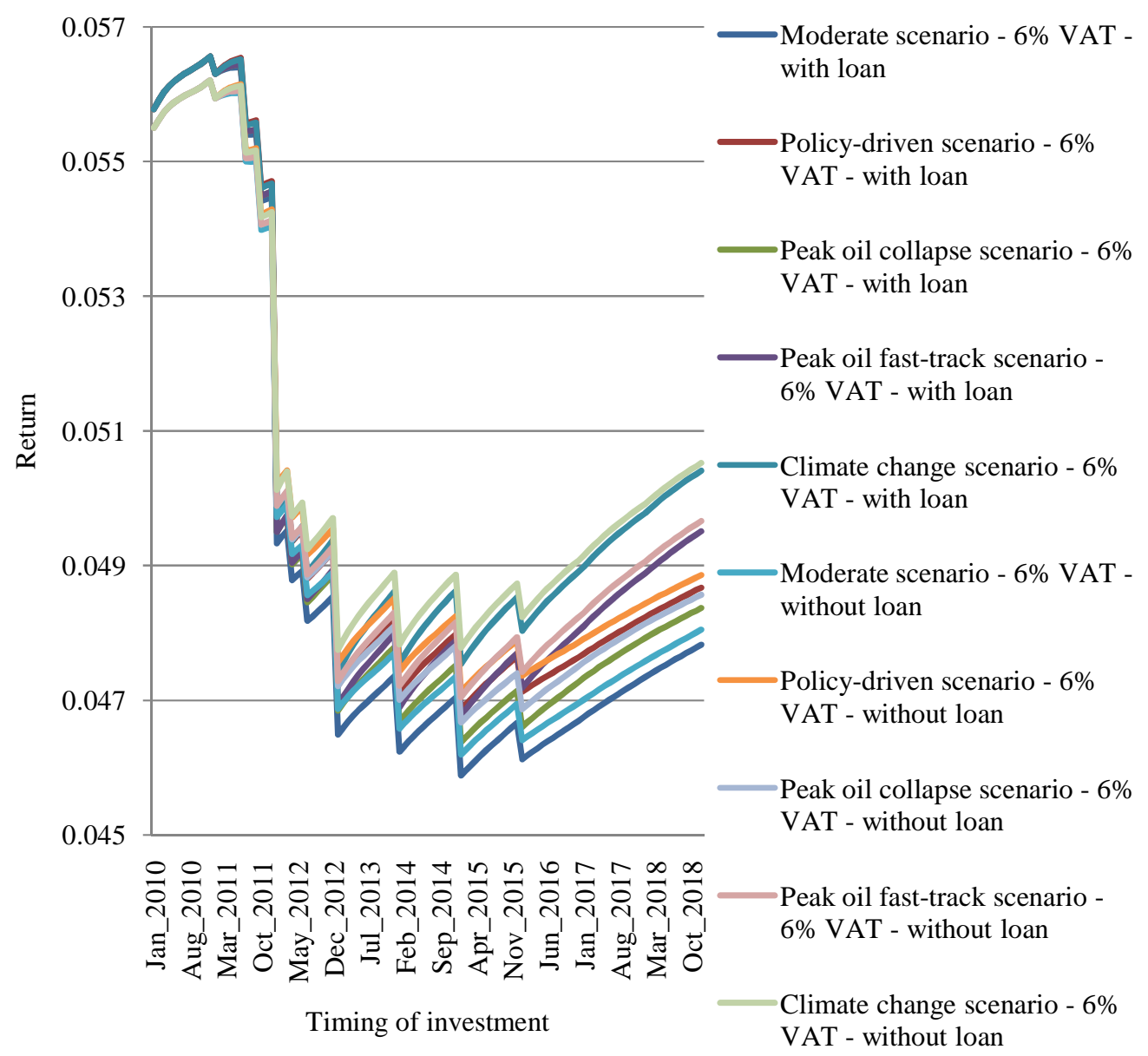

Figure 5: The return on the investment for the base scenario and VAT equal to $6 \%$ 


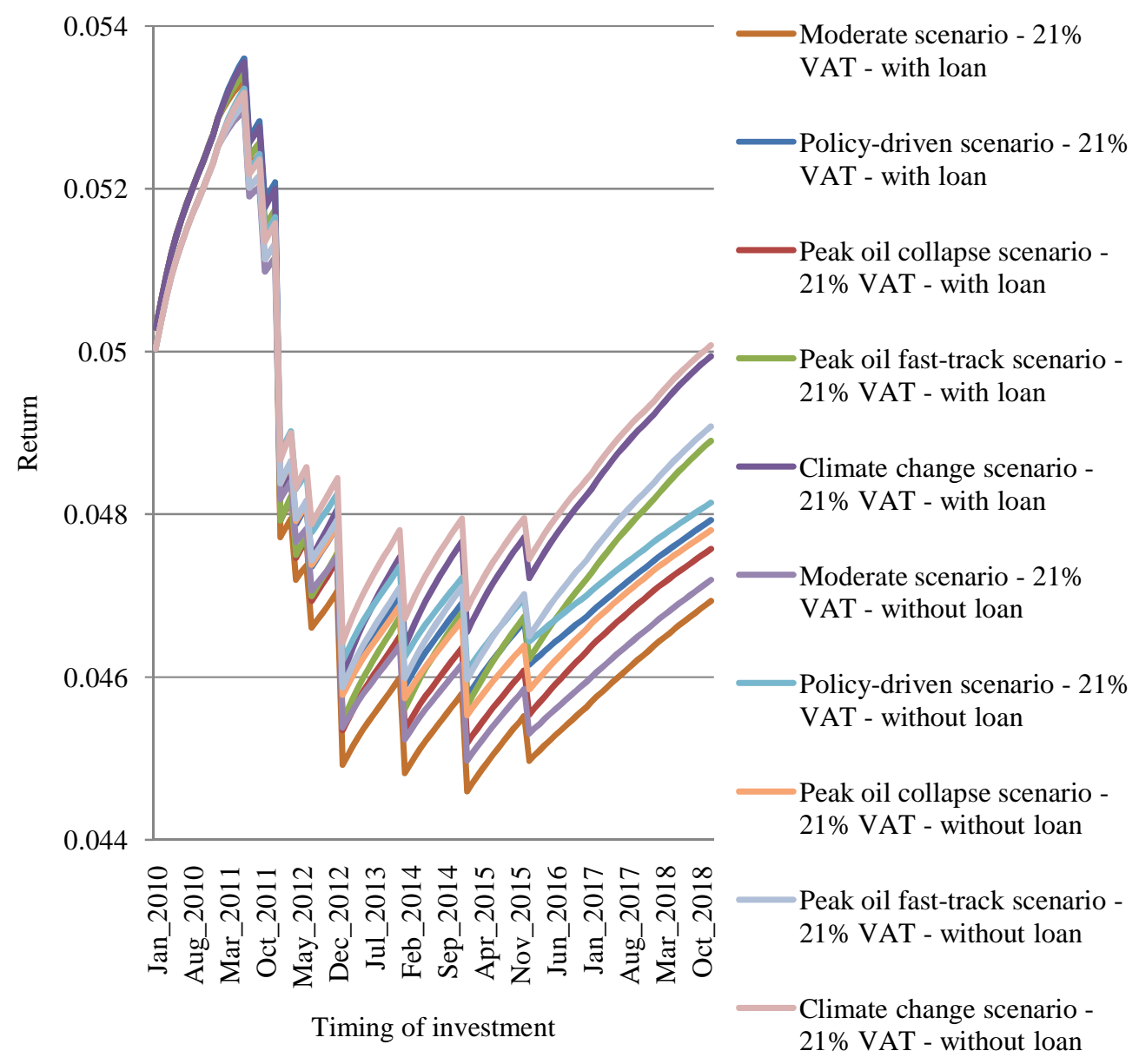

Figure 6: The return on the investment for the base scenario and VAT equal to $21 \%$

Fig. 7 illustrates that there are four main factors determining the yield of the investment: the green certificates, the energy cost savings, the tax revenues on the investment cost (when investing before 2012) and the revenue from investing later than January 2010. Note that the green certificate value and the tax revenues on the investment cost decrease considerably when investing later, but this decrease is largely compensated for by the yield when investing later in time. The energy cost savings only slightly increase. The figure clearly illustrates that all the subsidies granted are not needed in order to make the investment in PV panels profitable. Not investing generates a total future value of $64451.43 €\left(=S(1+d)^{33-1 / 12}\right)$. Figure 7 indicates that the energy cost savings (with a future value that is always above $56874.77 €$ ) alone cover a large part from the investment in PV panels. 


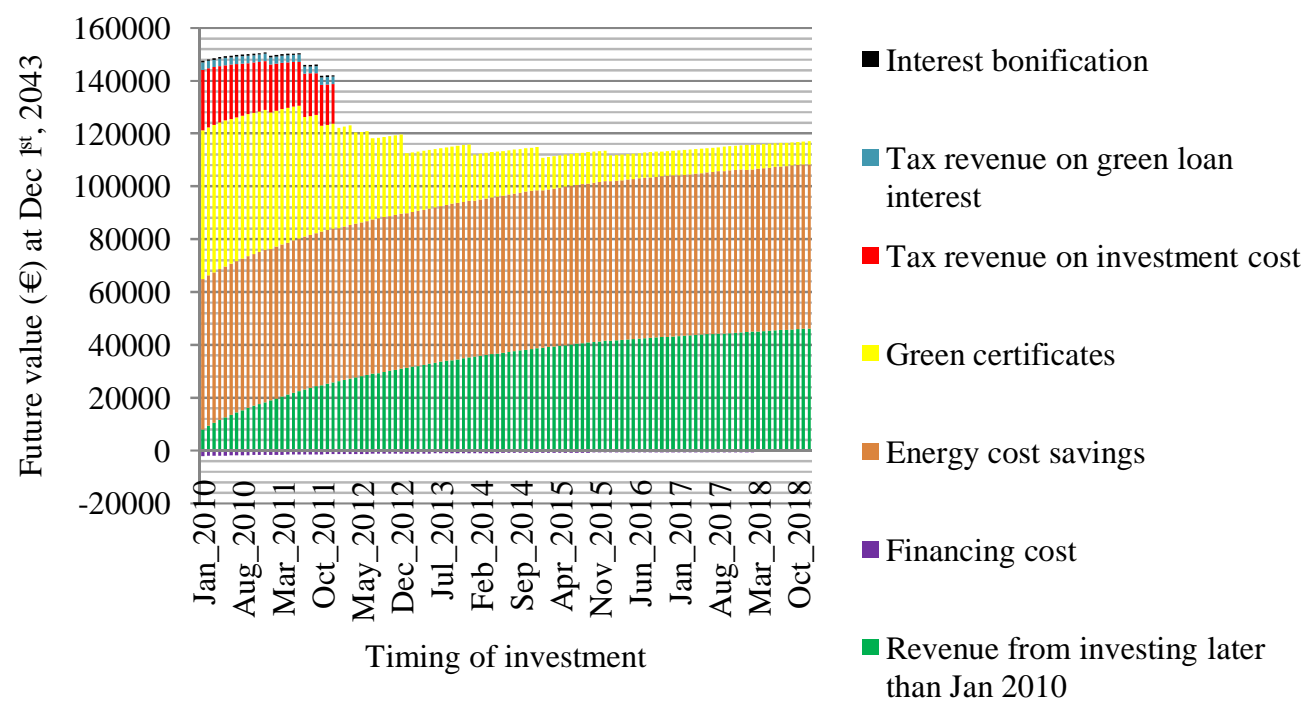

Figure 7: Breakdown of the future value (assuming the policy-driven scenario, $V A T=6 \%$, green loan and investment before 2012) in the base scenario

\subsection{Sensitivity analysis}

In this section, we investigate whether the optimal investment timing can change by altering the parameters of the base scenario (see Table 4). Note that we have already incorporated the following changes in Section 3.1: VAT percentage (6\% or 21\%), investment with (green) loan or without loan, evolution of the global cumulative production of PV panels (moderate, policy-driven, peak oil collapse, peak oil fasttrack or climate change scenario, which all impact the investment cost).

In order to simplify the figures, we will only concentrate on the policy-driven and peak oil fast-track scenarios in what follows. The figures for the moderate and peak oil collapse scenarios are similar to the policy-driven scenario, whereas the figure for the climate change scenario is similar to the peak oil fast-track scenario (see Fig. 1).

We subsequently discuss changes in the following parameters represented in Table 5.

Table 5: The parameter values for the sensitivity analysis

\begin{tabular}{llll}
\hline Parameter & Symbol & $\begin{array}{l}\text { Value base } \\
\text { scenario }\end{array}$ & Values sensitivity analysis \\
\hline Learning rate & $L R$ & $21 \%$ & $11 \%, 16 \%, 26 \%$ and $31 \%$ \\
Electricity price growth rate & $g$ & $4 \%$ & $0 \%, 1 \%, 2 \%, 3 \%, 5 \%$ and $6 \%$ \\
Degradation rate of PV panels & $z$ & $0.44 \%$ & $0.24 \%, 0.64 \%, 0.84 \%$ and $0.104 \%$ \\
Yield percentage & $l$ & $100 \%$ & $79 \%, 85 \%, 93 \%, 96 \%$ and $98 \%$ \\
Values of green certificates & $F_{m t}$ & Table 3 & $10 \%, 20 \%, 30 \%, 40 \%, 50 \%, 60 \%, 70 \%$,
\end{tabular}


Note that the parameters in Table 5 directly influence one or more of the three major elements (the green certificates, the energy cost savings and the yield by investing later) which constitute the future value of the investment as represented in Fig. 7.

In order to give an idea of the worst and best case for the base scenarios as compared to the scenarios of the sensitivity analysis (as represented in Table 5), we plot their future value in Figure 8. Note that we also represent "from 2012 on" because from this moment some subsidies will disappear.

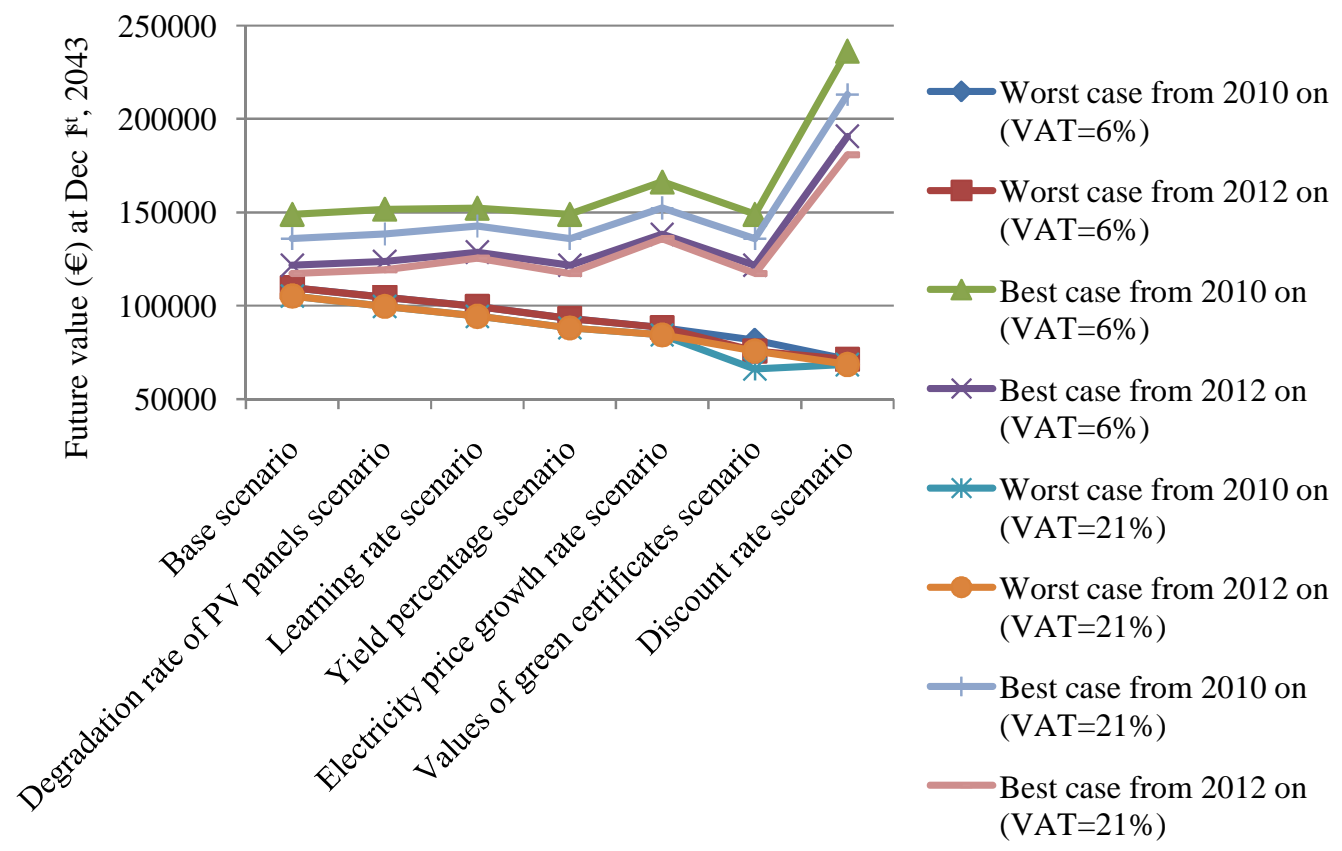

Figure 8: The future value of the worst and best case for the base scenario compared to the scenarios from the sensitivity analysis

Figure 8 clearly shows that the worst case scenarios from 2010 and 2012 on are equal to each other (for each VAT tariff), except for the green certificates scenario. This means that the worst case is situated after 2012 for all scenarios except for the green certificates scenario. Furthermore, it is worth noticing that the electricity price growth rate, the value of the green certificates and especially the discount rate have the greatest impact upon the future value. Indeed, an additional increase in electricity 
prices guarantees firmly increased profits. This is obvious as the electricity cost savings are one of the key components in the future value of the investment in PV panels. The other parameters do influence the future value but to a lesser extent.

With respect to the optimal timing of the investment panels for the best and worst cases (as represented in Fig. 8), we observe that the worst case is always situated in January $(2010,2012,2013$ or 2015). This is obvious as January is always a month in which the value of the green certificates are lowered. For the best case, only the learning rate (in the event that VAT equals 6\% and investing from 2010 on) and the electricity price growth rate (in the event that VAT equals 6\% and investing from 2012 on) scenarios differ from the base scenario.

Note that in carrying out the sensitivity analysis, we obtain robust results for the timing in investing in PV panels. The optimal timing is always December 2010 or June 2011 when investing from 2010 on. When investing in PV panels from 2012 on, the optimal timing remains March 2012 or December 2018.

\section{Conclusions}

The paper presents a model that investigates the optimal timing of investment in PV panels between 2010 and 2018 for the average Flemish household. A fixed amount for investment is assumed at the start of 2010. In order to compare the investment at different timings, we calculated the future value on December $1^{\text {st }}, 2043$ and the related returns. Apart from distinguishing between the VAT tariffs (6\% and 21\%), the timing of the investment (before 2012, between 2012 and 2013 and after 2013) and the forecast of the future prices of PV technology (moderate, policy-driven, peak oil collapse, peak oil fast-track and climate change scenario), we performed some sensitivity analysis on the most influential parameters of the model.

The results clearly show that investing in December 2010 or June 2011 gives the largest future value when investing before 2012 whereas March 2012 and December 2018 are the best periods to invest as of 2012. The discount rate is the most influential parameter, followed by the electricity price growth rate and the values of the green certificates.

The figures also point out that investing in PV panels was over-subsidized in 2010 and 2011 and will remain over-subsidized. As such, the abolition of the tax revenue on the investment cost at the end of November 2011 does not come as a surprise.

Apart from this over-subsidizing, the shape of the figures (U-shape) indicates that a 
cut in subsidies is likely to take place in the near future. It is important to obtain a decreasing trend in this future value when the government wants to stimulate households to invest in PV panels as soon as possible.

Finally, only the economic value of the investment was taken into consideration for this paper. It is well known that the investment also brings externalities. It is definitely true that PV panels repress $\mathrm{CO}_{2}$ emissions and can as such be seen as a step further towards reaching environmental goals such as the global Kyoto Protocol or the European 2020 20. This is a surplus for the investor and the community as a whole. At the same time, the production phase and disposal of these panels at the end of their useful life cause the dispersion of greenhouse gasses [23]. How to implement these environmental impacts in the model goes beyond this study and can be seen as a point for future research.

\section{References}

[1] T. Jackson, M. Oliver, The viability of solar photovoltaics, Energy Policy 28 (2000) 983-988.

[2] EPIA, Global Market Outlook for photovoltaics until 2015, (2011), Available from, http://www.epia.org/publications/photovoltaic-publications-global-marketoutlook.html [accessed July 2011].

[3] A. Audenaert, L. De Boeck, K. Roelants, Economic analysis of the profitability of energy-saving architectural measures for the achievement of the EPB-standard, Energy 35 (2010) 2965-2971.

[4] B. Ahuri, H. Kashani, J. Lu, A real options approach to evaluating investment in solar ready buildings, in: J.W.F. Wamelink, R.P. Geraedts, L. Volker L (Eds.), MISBE2011 - Proceedings of the international Conference on Management and Innovation for a Sustainable Built Environment, 2011.

[5] R. Bhandari, I. Stadler I, Grid parity analysis of solar photovoltaic systems in Germany using experience curves, Solar Energy 83 (2009) 1634-1644.

[6] A. McDonald, L. Schrattenholzer, Learning rates for energy technologies, Energy Policy 29 (2001) 255-261.

[7] G.F. Nemet, Beyond the learning curve: factors influencing cost reductions in photovoltaics, Energy policy 34 (2006) 3218-3232.

[8] F. Ferioli, K. Schoots, B. van der Zwaan, Use and limitations of learning curves for energy technology policy: A component-learning hypothesis, Energy Policy 37 
(2009) 2525-2535.

[9] J. Albrecht, The future role of photovoltaics: A learning curve versus portfolio perspective, Energy policy 35 (2007) 2296-2304.

[10] H. Radhi, On the value of decentralized PV systems for the GCC residential sector, Energy Policy 39 (2011) 2020-2027.

[11] A. Audenaert, L. De Boeck, S. De Cleyn, S. Lizin, J.F. Adam. An economic evaluation of photovoltaic grid connected systems (PVGCS) in Flanders for companies: A generic model, Renewable Energy 35 (2010) 2674-2682.

[12] H. Ren, W. Gao, Y. Ruan, Economic optimization and sensitivity analysis of photovoltaic system in residential buildings, Renewable Energy 34 (2009) 883-889.

[13] P.P. Singh, S. Singh, Realistic generation cost of solar photovoltaic electricity, Renewable Energy 35 (2010) 563-569.

[14] T. Wright, Factors affecting the cost of airplanes, Journal of the Aeronautical Sciences 3 (1936) 122-128.

[15] EPIA, Solar Generation, (2010), Available from, http://www.epia.org/publications/epia-publications/solar-generation-6.html [accessed July 2011].

[16] B. Lloyd, A.S. Forest, The transition to renewables: Can PV provide an answer to the peak oil and climate change challenges, Energy Policy 38 (2010) 7378-7394.

[17] EPIA. Solar Generation V. 2008. Available from http://www.epia.org/: http://www.epia.org/publications/archives/archives-publications.html [accessed July 2011]

[18] W. Lise, V. Linderhof, Electricity maket liberalisation in Europe - Who's got the power, IVM Report R-04/03, (2004), European Commission, Available from, http://hdl.handle.net/1871/9168 [accessed July 2011].

[19] W. Lise, G. Kruseman, Long-term price and environmental effects in a liberalised electricity market, Energy economics 30 (2008) 230-248.

[20] G. Hamm, A. Borison, Forecasting Long-Run Electricity Prices, The Electricity Journal 19 (2006) 47-57.

[21] S. Kaplanis, E. Kaplani, Energy performance and degradation over 20 years performance of BP c-Si PV modules, Simulation Modelling Practice and Theory 19 (2011) 1201-1211.

[22] KMI, (2011), Available from, http://www.meteo.be/meteo/view/nl/360955- 
Maandelijkse+normalen.html\#ppt_5238224 [accessed July 2011].

[23] E. Alsema, E. Nieuwlaar, Energy viability of photovoltaic systems, Energy Policy 28 (2000) 999-1010. 